International Journal of Automotive and Mechanical Engineering (IJAME)

ISSN: 2229-8649 (Print); ISSN: 2180-1606 (Online); Volume 8, pp. 1108-1120, July-December 2013

CUniversiti Malaysia Pahang

DOI: http://dx.doi.org/10.15282/ijame.8.2013.2.1108-1120

\title{
ENERGETIC AND EXERGETIC COMPARISON OF AIR TO AIR AND AIR TO WATER HEAT PUMPS ACCORDING TO EVAPORATOR CONDITIONS
}

\author{
Kemal Çomaklı ${ }^{1}$, UğurÇakır ${ }^{2}$, Erol Şahin ${ }^{3}$ and Ayşegül Çokgez Kuşs ${ }^{1}$ \\ ${ }^{1}$ Engineering Faculty, Mechanical Engineering \\ Department, Atatürk University, Erzurum / TÜRKIYE \\ Phone: +904422314849; Fax: +904422360957 \\ Email: kcomakli@atauni.edu.tr \\ ${ }^{2 *}$ Engineering Faculty, Mechanical Engineering \\ Department, Bayburt University, Bayburt / TÜRKIYYE \\ Email: *ucakir@bayburt.edu.tr \\ ${ }^{3}$ Vocational School of Technical Sciences, Ordu University \\ Ordu / TÜRKIYYE \\ Email: esahin1972@gmail.com.tr
}

\begin{abstract}
This paper presents an experimental energetic and exergetic comparison for a heat pump system that can be run in different modes as air to air and air to water. Components of the heat pump do not change when the running mode changes, except for the condenser. This means that some external and internal effects (like compressor type, pipe lines) that can affect the system performance will be the same for each running mode. The comparison which was made in this study demonstrates which system leads to an efficient conversion and supply of energy and exergy. In the analysis, four balance (mass, energy, entropy and exergy) equations are applied to the system for the two modes. Exergy and energy efficiency values for both systems are given, while exergy destructions in each of the systems are determined and presented. It is seen that the heat pump unit which has the highest COP value is the air to air type (3.45-3.8); second is the air to water type (3.35-3.41). The exergy efficiency of the air to air heat pump (29$32 \%$ ) is higher than the exergy efficiency of the air to water type heat pump (24.1-25). Ranking of the exergy destruction rates of the two heat pump types from high to low is as follows: air to air and air to water.
\end{abstract}

Keywords: Heat pump; heat pump comparison; exergy; energy saving.

\section{INTRODUCTION}

Heat pumps are systems which have been widely used for years around the world, especially in developed countries, because of their higher energy utilization and high efficiency. The use of energy in buildings for heating and cooling is nearly one third of the total energy consumed in the world. Due to growing concern about this, the use of fossil fuels which will be depleted soon, and because of sustainability issues, an alternative energy source must be found to meet the heating/cooling energy needs of buildings. This situation has led researchers to study systems that use energy more efficiently, more economically and decrease the cost of energy, such as heat pump systems (Kavanaugh, 1989; Kavanaugh, Woodhouse, \& Carter, 1991). Heat pump systems are used for heating or cooling applications in buildings due to their high energy effectiveness and reliability. The technical and thermophysical characteristics of 
heat sources or heat sinks used directly have an important role in the technical and economic performance of heat pumps. The heat sources and heat sinks which are commonly used or preferred in practical applications are ambient air, lake water, river water, soil, rock, waste-water and effluent, and exhaust air. The heat pumps which use air or water as the heat source/sink have attractive performance and usability characteristics when designed and installed properly. Additionally, these systems are considered a viable alternative to conventional cooling and heating systems. They offer many performance advantages over many other heat pumps due to the outstanding heat transfer properties of water and the much more favorable temperatures of river or lake water or exhaust air. The advantages and disadvantages of water-source heat pump systems have been discussed previously by several researchers (Büyükalaca, Ekinci, \& Yilmaz, 2003; Kavanaugh \& Pezent, 1990; ASHRAE, 1992). The most commonly used heat source for heat pumps is ambient air. Ambient air is free, widely available and it can be found everywhere. However, the capacity and performance of air-source heat pumps decreases rapidly with decreasing ambient temperature during the heating season, and with increasing ambient temperature during the cooling season (Çakır \& Çomaklı, 2011; Çomaklı \& Çakır, 2011).

Many studies and investigations have reported in the open literature on different types of heat pumps and on comparison of them. These comparisons were made experimentally or by simulations, according to their heat sources, heat sinks, and the place where they were being used, the refrigerant used as working fluid, and the structures and capacities of components in general. For instance, Bakirc1 et al. conducted a study to investigate the performance of a solar-ground source heat pump system in the province of Erzurum. The COP of the heat pump and the system were found to be in the range of 3.0-3.4 and 2.7 to 3.0, respectively. It was also claimed that the system investigated could be used for residential heating in the province of Erzurum, which is a cold climate region of Turkey (Bakırc1 et al., 2011). Urchueguia made an experimental comparison between a ground-coupled heat pump system and a conventional air to water heat pump system, focusing on the heating and cooling energy performance. For the whole climatic season, the results obtained demonstrated that a ground source heat pump system is a viable and energy-efficient alternative to conventional systems for heating and cooling applications in the South European regions. In most comparative studies, heat pump systems are compared according to their thermodynamic performance depending on the refrigerant type used (Urchueguia et al., 2008). Another paper presents an untreated sewage source heat pump (USSHP) system in which auto-avoiding-clogging equipment is used to continuously capture suspended solids in the sewage. Thus, the blockage problems caused by filtration and fouling in the heat exchanger tubes can be efficiently resolved in this system. In an actual engineering application, the characteristic parameters of a USSHP system are tested under typical operating conditions for heating status. Based on the test results, the performance of the USSHP system is examined. The results indicate that the thermal resistance of the convective heat transfer and fouling on the sewage side in the sewage exchanger is $80 \%$ of its total thermal resistance (Rana, \& Thakur, 2012; Banyal, \& Sharma, 2013; Muthucumaraswamy, \& Velmurugan, 2013; Liu, Ma, \& Zhang, 2014). One study aims to evaluate the most suitable GSHP system configurations in the case of high humidity soils and yearly balanced heat transfer at the ground side. This analysis takes advantage of a case study sited in Venice and consisting of the restoration of an historical building. In this analysis the GSHP system performance is calculated both in heating and in cooling conditions using detailed simulation software developed by the 
authors and aimed at modeling the heat pump and the borehole heat exchanger (Schibuola et al., 2013). Venkataramanamurthy and Kumar conducted a study which presents an experimental comparison of energy, exergy flow, and second law efficiency of R22 and its substitute R436b (hydrocarbon mixture of 52\% propane (R290) $48 \%$ isobutene (R600a)) vapor compression refrigeration cycles. The energy flow of various points in the refrigeration cycle, and the efficiency and second law efficiency for both R22 and R436b refrigeration cycles were compared. The results were presented graphically and showed the location of inefficiencies (Venkataramanamurthy \& Kumar, 2010).

In another study, the performance of a cascade heat pump water heating system was investigated with a quasi-steady state analysis to find out the transient behavior of the system. The water-heating system consists of the cascade heat pump water heater, which uses R134a and R410A as refrigerants, and a water storage tank. The steady-state cascade heat pump model was developed based on experimental results and the dynamic storage tank model was created using thermodynamic equations. The model computes the several major parameters related with the system performance, such as the heating capacity, the power consumption, the COP (coefficient of performance), and the temperature distribution in a storage tank. Moreover, the performance of the system is calculated for various conditions to research the influence of ambient temperature and hot water demand (Park, Kim, \& Kim, 2013). In Waheed et al.'s (2014) study, enhanced VRHP models were developed to reduce the heat loss and heat pump size. The strategies adopted rely on reducing the heat differential across the heat pump by utilizing external and utility streams, and a process stream within the system. The thermo-economic and environmental performances of the developed models were compared with the base case VRHP and the conventional distillation process. The results showed that the developed models yielded considerable energy savings. Considering the present trend of short process modification payback time, the use of an external process stream is recommended as the best option to boost the plant performance. In this paper, an experimental performance study was conducted on a traditional vapor compressed refrigeration system that can be run in either air to air mode or air to water mode with the help of a valve. The experiments were run under different thermal conditions. The thermodynamic performance of the systems is presented and compared for the different working conditions. The research evaluated and compared the energetic and exergetic performance of the heat pump systems in the two different modes, air to air or air to water, when using only one compressor.

\section{CALCULATION AND EXPERIMENTAL WORK}

Since this study focuses on comparing the exergy treatments of two different heat pump systems, air to air and air to water, an exact and detailed exergy analysis is required. In addition, this analysis focuses on evaluating some representative figures which in general can be extrapolated for all heat pump modes with reasonable accuracy and simplicity.

\section{Evaluation of Heat Pump Characteristics}

All of the measured values were used to determine the energetic and exergetic performance. In order to make a healthy exergy analysis, it is first necessary to make an energy analysis. Mass, energy and exergy balances are employed to determine the heat 
input, the rate of exergy destruction, and energy and exergy efficiencies. From the measured parameters, general energy and exergy calculations of the systems are made as follows (Rosen \& Dinçer, 2004; Dinçer \& Rosen, 2007). The heat delivered by the condenser to the air or water is calculated by

$$
\begin{aligned}
& \dot{Q}_{\text {con-air }}=\dot{m}_{a} C p_{a}\left(T_{\text {ca out }}-T_{\text {cain }}\right) \\
& \dot{Q}_{\text {con-water }}=\dot{m}_{w} C p_{w}\left(T_{c w o u t}-T_{c w i n}\right)
\end{aligned}
$$

The heat extracted by the evaporator from the air or water is calculated by

$$
\dot{Q}_{\text {evap-air }}=\dot{m}_{a} C p_{a}\left(T_{\text {eain }}-T_{\text {eaout }}\right)
$$

The power input to the compressor is calculated by

$$
\dot{W}_{\text {Comp elec }}=\sqrt{3} \cdot \operatorname{Cos}(\varphi) \cdot U \cdot I
$$

where U, I and $\operatorname{Cos}(\varphi)$ are voltage $(\mathrm{V})$, current $(\mathrm{A})$ and power factor, respectively. The coefficient of performance (COP) for any heat pump

$$
C O P_{\mathrm{HP}}=\frac{\dot{Q}_{\text {Cond }}}{\dot{W}_{\text {comp elec }}+\dot{W}_{\text {fan elec }}}
$$

\section{System Exergy Analysis}

Energy and exergy balances can be written as

$$
\begin{array}{r}
\dot{E}_{\text {in }}=\dot{E}_{\text {out }} \\
\dot{E} x=\dot{m} . e x \\
\dot{E} x_{\text {in }}-\dot{E} x_{\text {out }}=\dot{E} x_{\text {dest }}
\end{array}
$$

The specific flow exergy of the refrigerant and water is evaluated as

$$
e x_{r, w}=\left(h-h_{0}\right)-T_{0}\left(s-s_{0}\right)
$$

where $h$ is enthalpy, $s$ is entropy and the subscript zero indicates properties at the reference (dead) state. The total flow exergy of air is determined as (Dinçer \& Rosen, 2007)

$$
\begin{aligned}
e x_{\text {air }}= & \left(C p_{a}+\omega C p_{\text {vapor }}\right) T_{0}\left[\left(\frac{T}{T_{0}}\right)-1-\ln \left(\frac{T}{T_{0}}\right)\right]+(1+1.6078 \omega) R_{\text {air }} T_{0} \ln \left(P / P_{0}\right) \pi \\
& +R_{\text {air }} T_{0}\left\{(1+1.6078 \omega) \ln \left[\left(1+1.6078 \omega_{0}\right) /(1+1.6078 \omega)\right]+1.6078 \omega \ln \left(\omega / \omega_{0}\right)\right\}
\end{aligned}
$$


Exergy efficiency and exergy destruction of the heat pumps are as follows:

$$
\begin{gathered}
\eta_{e x, H P}=\frac{\dot{E} x_{\text {heat }}}{\dot{W}_{\text {in elec }}}=\frac{\dot{E} x_{\text {in cond }}-\dot{E} x_{\text {outcond }}}{I \cdot U \cdot \operatorname{Cos}(\phi) \cdot \sqrt{3}} \\
\dot{W}_{\text {in elec }}=\dot{W}_{\text {comp elec }}+\dot{W}_{\text {fans elec }} \\
\dot{E} x_{\text {dest HP }}=\sum \dot{E} x_{\text {in HP }}-\sum \dot{E} x_{\text {out HP }}
\end{gathered}
$$

\section{Experimental System and Uncertainties}

Figures 1a and $1 \mathrm{~b}$ show the schematic diagram and real view of the experimental apparatus. The system was originally designed to operate with $\mathrm{R} 22$. The main components of the system are a scroll compressor, an air cooled evaporator, an air cooled condenser, a water cooled condenser, thermostatic expansion valve, and other elements like measurement and control equipment. In addition, electrical air and water heaters are used in order to keep the temperature of air and water passing into the evaporator and condensers at the desired levels. Two electrical fans are used to circulate the air on the evaporator and condenser, which is air cooled. By using the estimation method of Kline and McClintock (1953) and Çakır (2011), maximum uncertainties of the COP and exergy efficiency are found as follows: COP, 3.53\%; exergy efficiency, $3.53 \%$. The individual contributions to the uncertainties of the COP and exergy efficiency for each of the measured physical properties are summarized in Table 1.

Table 1.Uncertainties in the values of the relevant variables.

\begin{tabular}{lc}
\hline \multicolumn{1}{c}{ Variables } & Uncertainty $(\%)$ \\
\hline Temperature $(\mathrm{T})$ & 2.5 \\
Pressure $(\mathrm{P})$ & 1.6 \\
Voltage $(\mathrm{U})$ & 1.7 \\
Current $(\mathrm{I})$ & 1.7 \\
Power factor $(\operatorname{Cos} \varphi)$ & 1.7 \\
Mass flow rate $\left(\mathrm{m}_{\mathrm{r}}\right)$ & 1,3 \\
\hline
\end{tabular}

The temperature and pressure of the working fluid were measured at several points of interest, as shown in Figure 1a. K-type nickel thermocouples were used to measure the temperatures of the working fluid and the thermocouples were calibrated with a digital temperature controller. The working fluid temperatures are measured at the inlets and outlets of the evaporators, condensers and compressor. Four thermocouples were used at different points of every entrance and exit of the air channels to determine air temperatures correctly at the inlet and outlet of the air cooled evaporator and air cooled condenser. Measurement of the temperature and humidity of outdoor air was recorded for every test. Only one data logger was used to determine and record all the temperature measurements which were obtained from the system. 


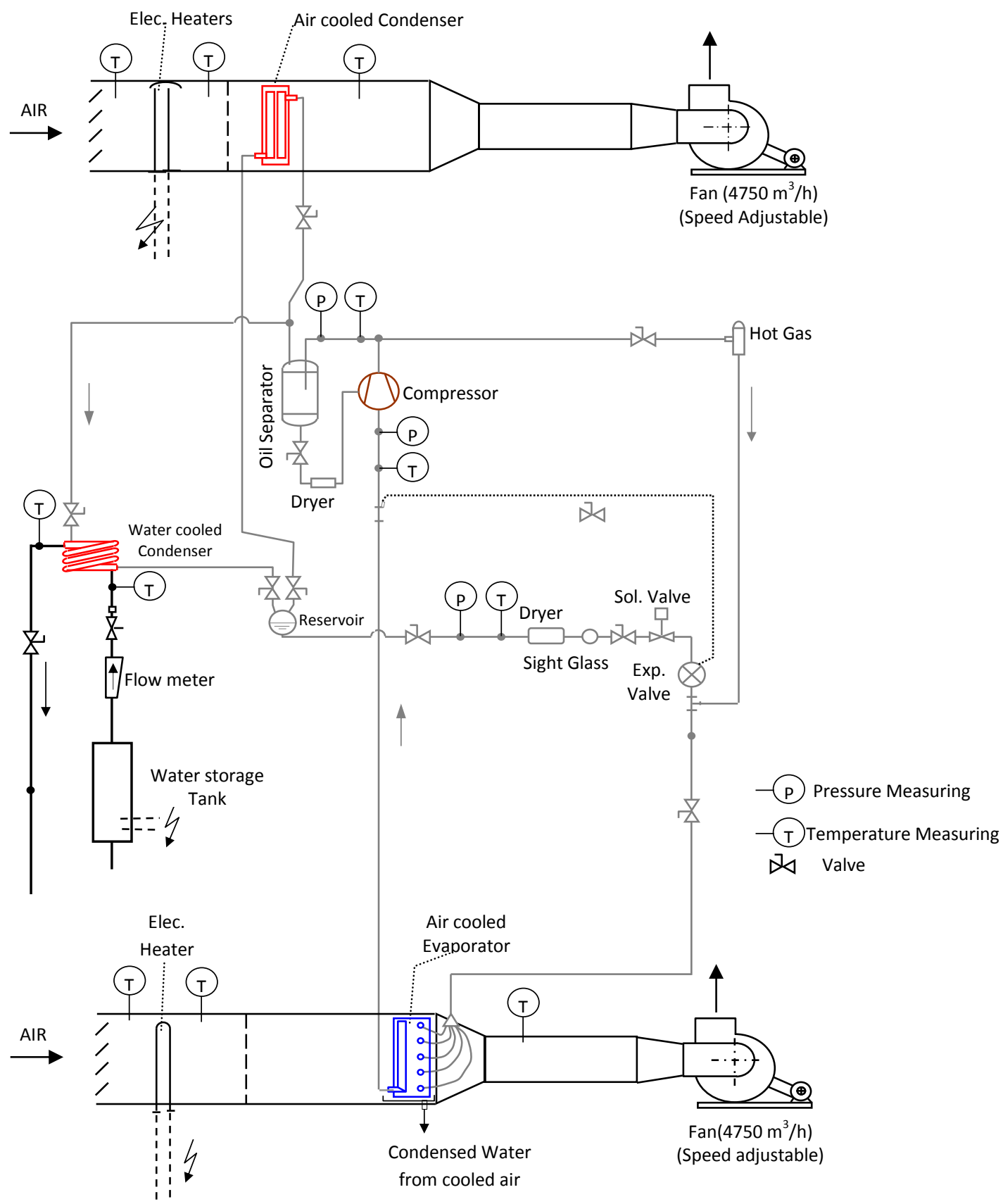

Figure 1a. Schematic view of the experimental setup
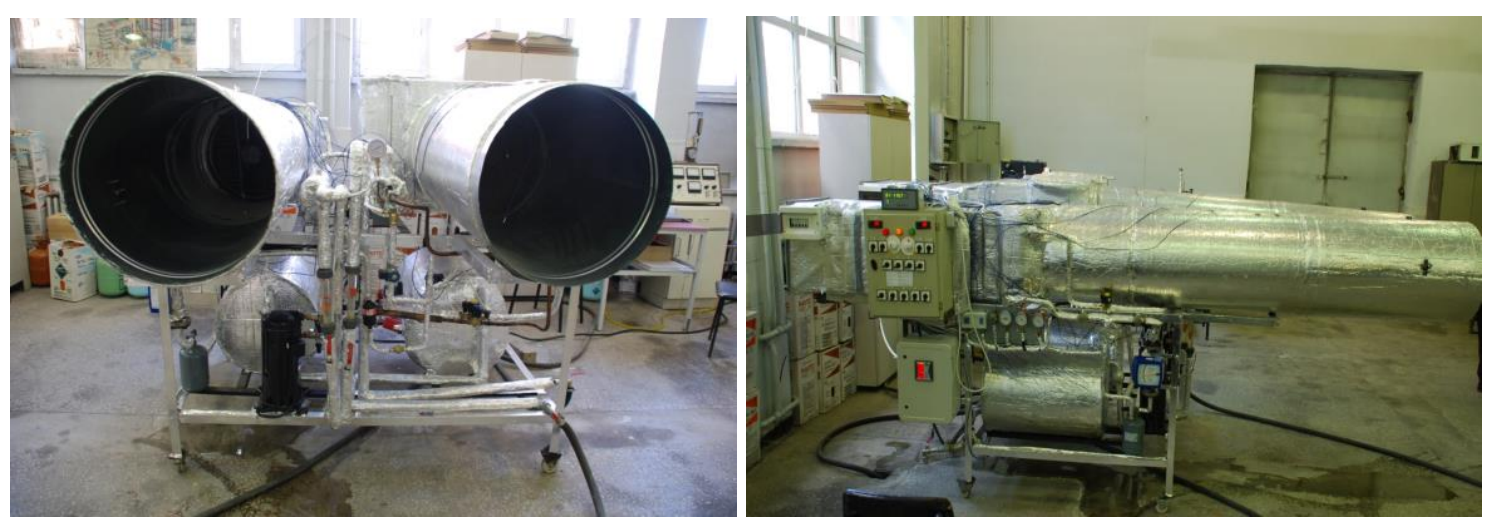

Figure 1b. View of the experimental setup 
Six bourdon type manometers were installed at the inlets and outlets of the condensers, evaporators, and compressor to measure the pressures of the working fluid. Measurement of flow rate of the water was done by using two rotameters, the flow rate of the working fluid used in the cycle was determined with a flow meter, and the air flow was measured using an anemometer. Compressor input current and voltage was obtained using a multifunctional amperemeter and wattmeter which can in addition show the Cos $(\varphi)$ value. The system was charged only once for all tests with 15 Bar R22 while all the valves were in the opened position at the temperature of the external air. When the system is to be run in the other heat pump mode, it is necessary to close the required valves. When the tests were completed for one mode and it was required to convert the system to the other mode, we opened all of the valves on the system and waited for one day. Then we closed the required valves for the new mode and ran the new tests. The tests were performed under laboratory conditions, during which the air temperature was about $20-22^{\circ} \mathrm{C}$, and the relative humidity was about $30-40 \%$. Each experiment was repeated at least three times under the same conditions at different times.

\section{RESULTS AND DISCUSSION}

Two different heat pump systems were designed to run on the same experimental setup and have the same heating capacity, using just one compressor and being controlled by the same control equipment. The same measurement system was used. They were compared experimentally and exergetically with each other by using the second law of thermodynamics. Within the scope of the study presented here, the COP, exergy efficiency and rate of exergy destruction of the heat pump types were evaluated, discussed and compared as the results of this paper. Energetic and exergetic performance differences between the two different heat pump types, according to the increasing rate of temperature and according to the flow rate of the fluid used as heat source, are expressed and compared.

Figures 2 and 3 show the change in the COP values of the two heat pump units depending on the increasing rate of temperature and mass flow rate levels of the air which is used as the heat source. As seen in the figures, the heat pump unit which has the highest COP value is the air to air type; second is the air to water type. As it is known, heat pumps are systems which transfer the heat from a low-temperature medium to a high-temperature medium.

It is well known that the COP of heat pumps increases depending on the increase in the heat source temperature. When two heat pump types are compared, there is a greater increase in the COP value of the heat pumps which use air as the condenser fluid (air to air type) than in the COP of the other type which uses air to water. The mass flow rate of the fluid used as the heat source has a major importance for the performance of the heat pumps. It is known that heat transfer is improved with increasing flow rate. It is understood from Figure 3 that the COP of the heat pumps decreases with the increasing of the mass flow rates of the fluid used as the heat source. This situation may be due to the high air velocity in the evaporator. The time required for heat transfer decreases with increase in air velocity. At the same time, this is mainly due to the absence of the energy consumption of fans. 


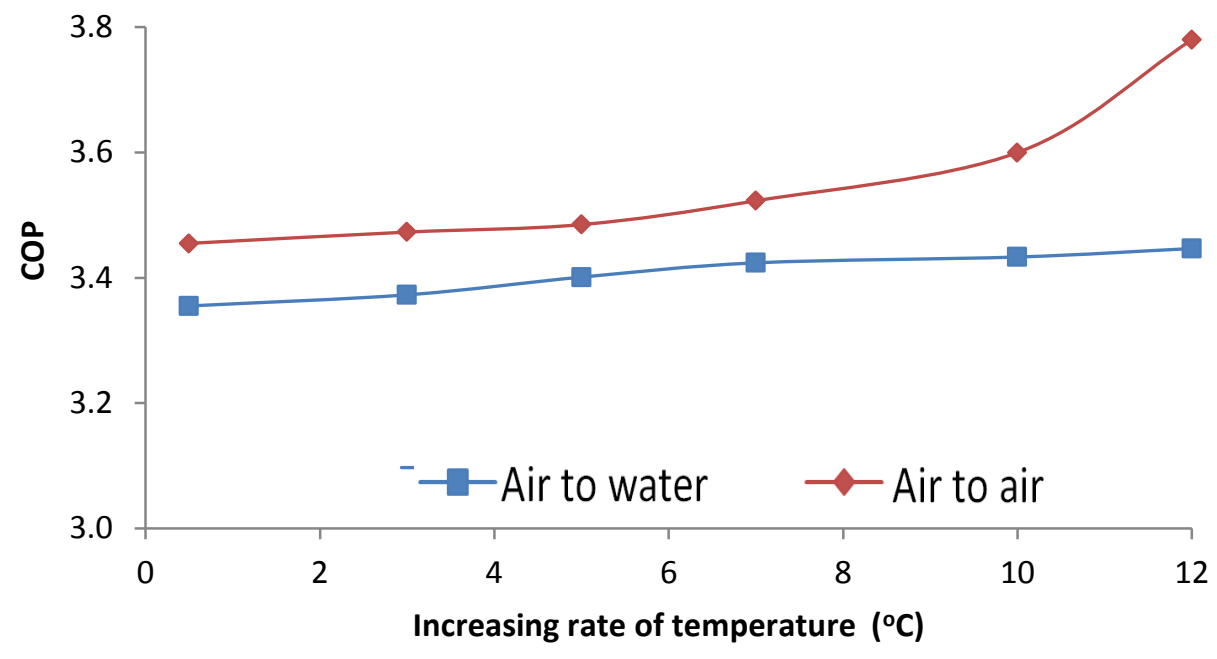

Figure 2. COP change of heat pumps versus increasing temperature of the evaporator fluid

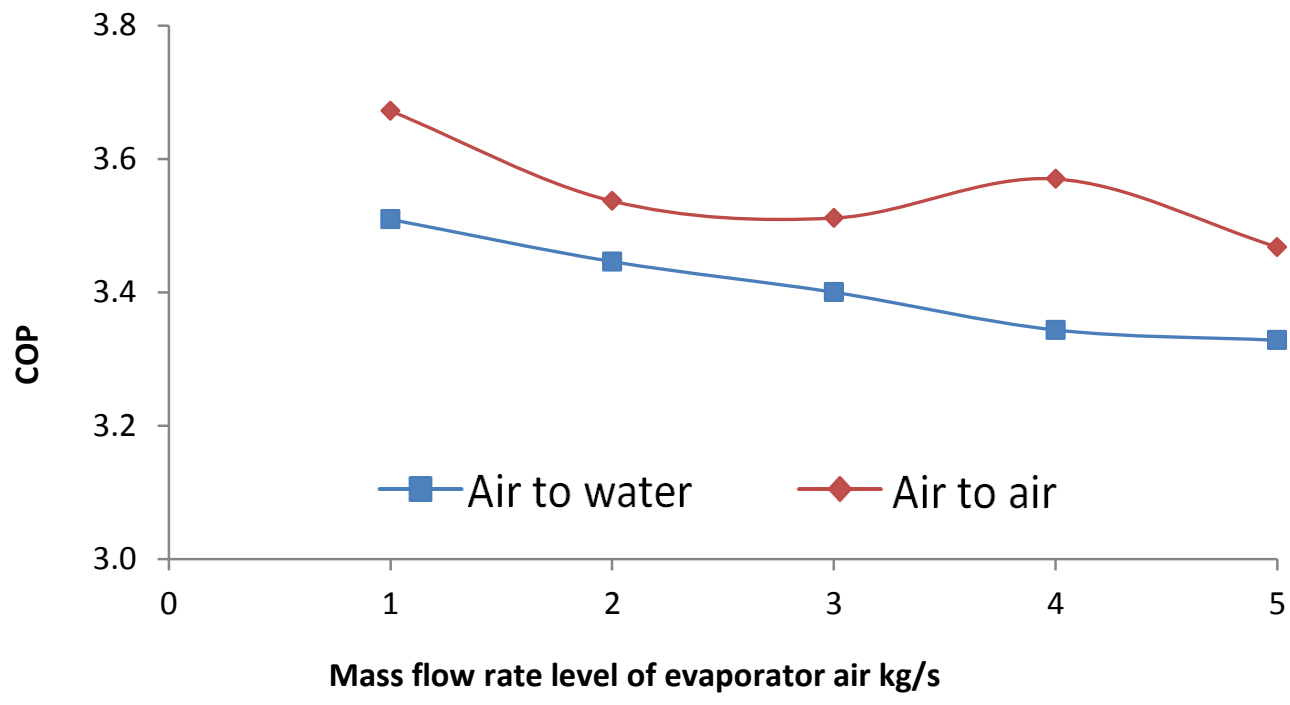

Figure 3. COP change of heat pumps versus increasing of mass flow rate of the evaporator fluid

The exergy efficiency of the air to air heat pump is higher than the exergy efficiency of the air to water type heat pump, as presented in Figure 4. The heating capacities of the two heat pump types can be synchronized easily by adjusting the mass flow rate and temperature of the condenser fluid, even if the temperature of the refrigerant entering the condenser is at different levels. The amount of the heat energy given to the condenser fluid from the heat pump is controlled by this adjustment, but the amount of the exergy given to the condenser fluid from the heat pump cannot be controlled, since the exergy is not the only property of the systems. It is a property of the combined system and surroundings. The exergy of a fluid is related to the properties of the surroundings as dead state temperature. The difference between the temperature of the surroundings and the temperature of the fluid determines the exergy of the fluid. The mass flow rate and temperature of the air and water which are used as condenser cooler must not be equal if it is desired to synchronize the heating capacity of the heat 
pump systems. For that reason, the amount of exergy given to the air from the condenser is higher than the exergy given to the water. That is why the exergy efficiency of the heat pumps using air as external fluid in the condenser is higher than the other.

The variations of the heat pump exergy efficiencies depending on the increases in mass flow rates of the heat source fluid can be seen in Figure 5. The exergy input of the compressor depends on the temperature of the refrigerant which comes from the evaporator. When the refrigerant enters the compressor at a higher temperature, it becomes much more difficult to transfer exergy and energy to the refrigerant from the compressor and thus the compressor causes an increase in the temperature of the refrigerant to the higher levels. Increasing the mass flow rate of the evaporator fluid makes the compressor use more energy and that situation causes more exergy input to the system. After the mass flow rate of the evaporator fluid increases to the second level or more, the compressor consumes much more energy, but simultaneously it causes a much greater rise in the refrigerant temperature at its exit. For that reason, more exergy is given to the condenser fluid and the exergy efficiency increases.

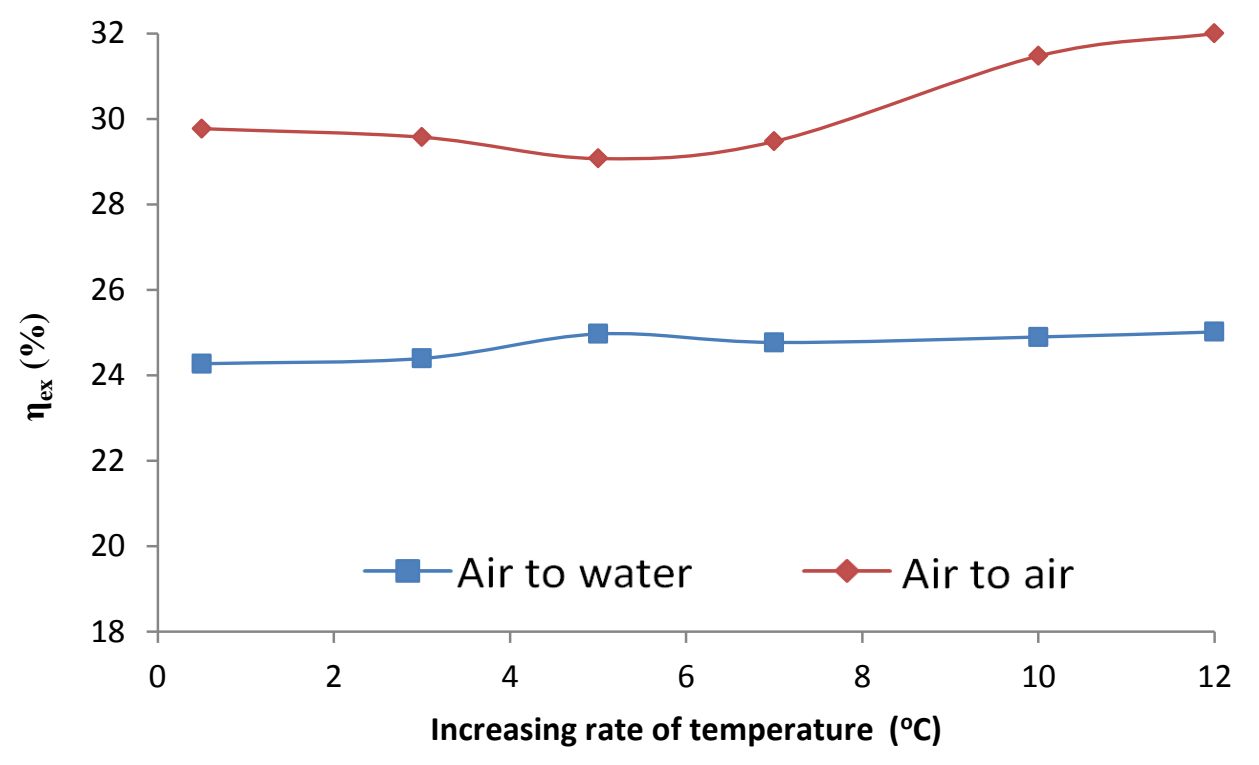

Figure 4. Exergy efficiency change of heat pumps versus increasing of heat source temperature

Figure 6 shows the exergy destruction rate changes of the two systems according to the conditions of the evaporator fluid. As seen in the figure, ranking of the exergy destruction rates of the two heat pump types from high to low is as follows; air to air and air to water. As seen in the figure, the rate of exergy destruction of the air to water heat pump is being affected more than the other, depending on the increase in the heat source temperature. It is understood from Figure 7 that the mass flow rate of the fluid used as the heat source is more effective on the exergy destruction rates of the heat pumps.

The exergy destruction in any component of the heat pump is not caused only by its inefficiencies, but also depending on the inefficiencies of other system components. In the figures, we can clearly see the change of exergy destruction rates of the systems based on the results of the tests, but the contributions of the various components to the 
total exergy destruction of the system must be taken into account in order to comment on these figures. The largest exergy destruction of the heat pump systems occurred in the condenser, followed by the compressor, evaporator and expansion valve. When air is used as the evaporator fluid, the exergy destruction of the systems becomes higher than other types due to the increase of exergy destruction in the compressor and condenser. As mentioned before, using air at the evaporator causes an increase in the refrigerant temperature in the compressor and in the condenser. In addition, the effect of the exergy destruction rate of air fans must be taken into account. As seen in Figure 7, the exergy destruction of heat pump systems which use air at the evaporator increases with the increase in the mass flow rate of air due to the increase in the exergy destruction rate of the evaporator and fans.

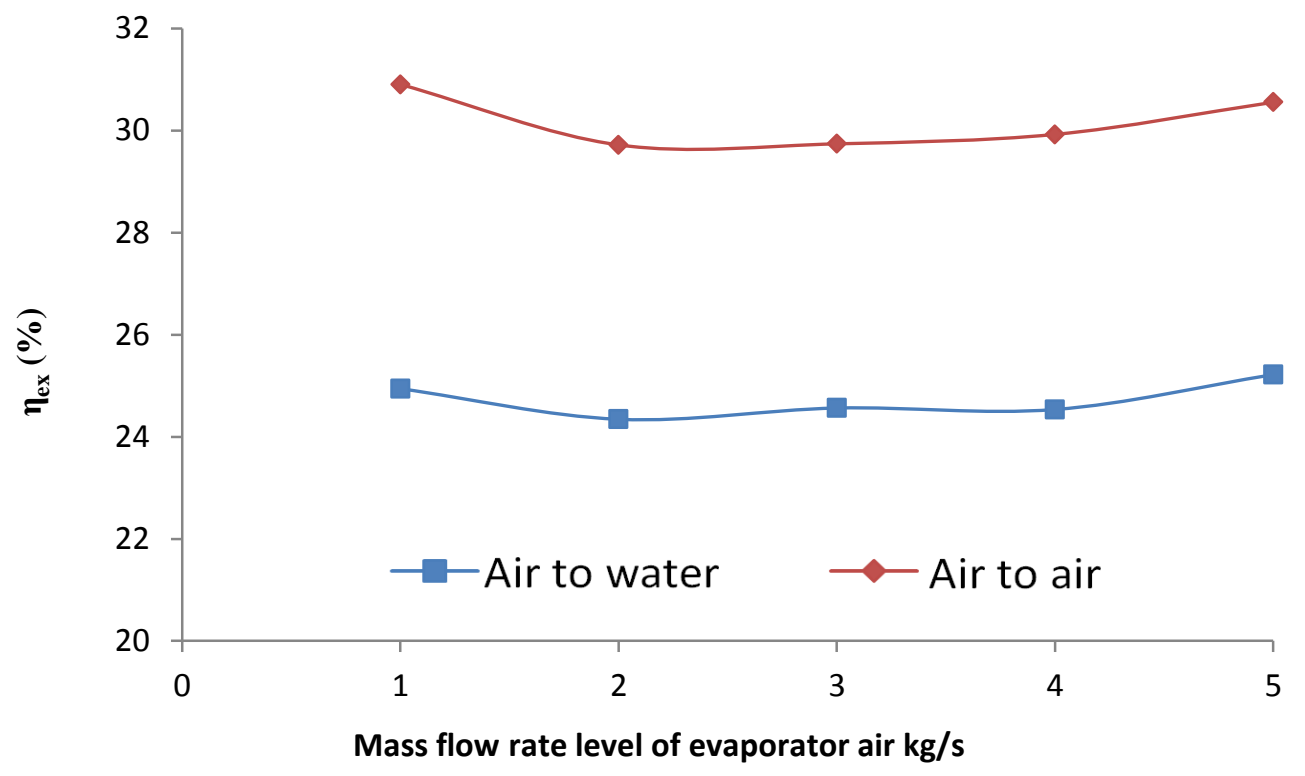

Figure 5. Exergy efficiency change of heat pumps versus increasing of mass flow rate of the evaporator fluid

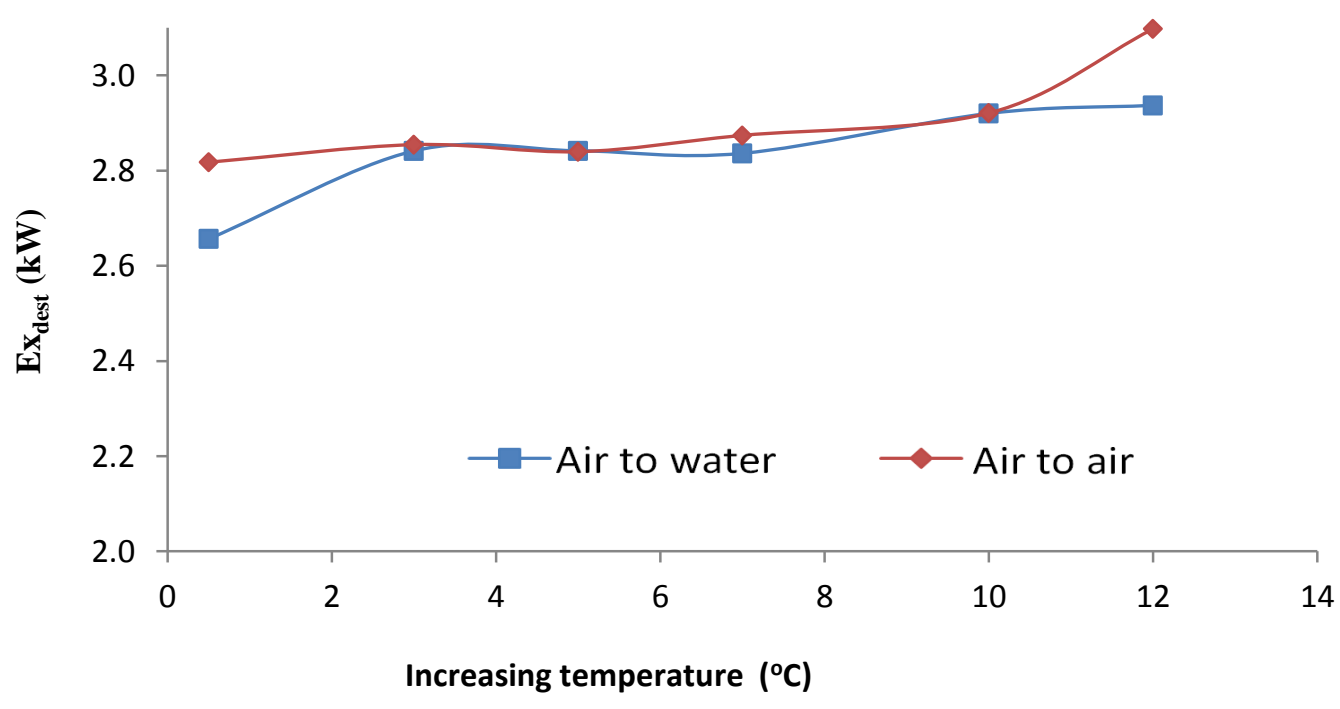

Figure 6. Exergy destruction rate change of heat pumps versus increase of the evaporator fluid temperature 


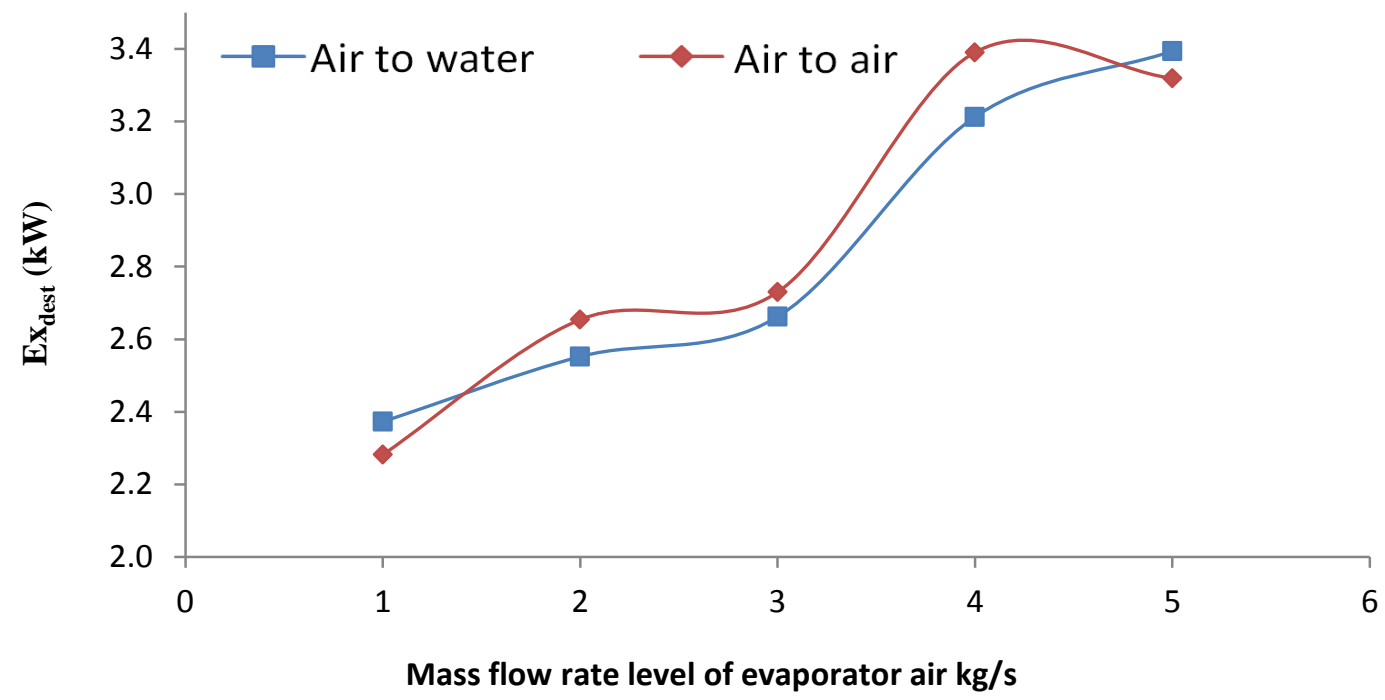

Figure 7. Exergy destruction rate change of heat pumps versus increase of the mass flow rates of evaporator fluid

\section{CONCLUSION}

In this paper, energy and exergy analysis of two different heat pump types (air to air, air water) was investigated, regarding the temperature and mass flow rate changes of the evaporator fluid which is used as the heat source. The coefficient of performance of the heat pumps primarily depends on the temperature of the heat source. In addition, it depends on the mass flow rate of the heat source fluid. The COP of the air to air type heat pump is higher than the air to water type. The mass flow rate of the heat sink has a greater effect on the COP change of the heat pump than temperature.

It is understood from the study that the exergy efficiency of the air to air heat pump system is higher than that of the air to water type heat pump. This ranking is similar to the result for the COP ranking. For that reason, it can be said that air to air heat pumps perform better than air to water pumps, because the two different performance criteria show us the same result. Variations of the exergy efficiency and exergy destruction of the systems according to the evaporator fluid temperature and according to the mass flow rate differ from each other. But the result of the exergy destruction analysis supports the opinion mentioned before. When air is used at the evaporator, the change in the mass flow rate causes a serious increase in the exergy destruction of the system.

\section{ACKNOWLEDGEMENTS}

This work was supported by the Turkish Scientific and Technological Research Council of Turkey (TUBITAK Project No. 105M030) and Ataturk University, Research Project Foundation (Project No. BAP-2005/16). The authors wish to thank TUBITAK and Ataturk University 


\section{REFERENCES}

ASHRAE (1992). Systems and Equipment Handbook (SI) [chapter 47].

Bakirci, K., Ozyurt, O., Comakli, K., \& Comakli, O. (2011). Energy analysis of a solar ground source heat pump system with vertical closed loop for heating applications. Energy, 36(5), 3224-32.

Banyal, A. S., \& Sharma, D. K. (2013). On thermal convection of Rivlin-Ericksen fluid in the presence of vertical rotation. Journal of Mechanical Engineering and Sciences, 4, 462-471.

Büyükalaca, O., Ekinci, F., \& Y1lmaz, T. (2003). Experimental investigation of Seyhan River and Dam Lake as heat source-sink for a heat pump. Energy, 28(2), 15769.

Çakır, U. (2011). Exergetic comparison of heat pumps according to fluids used in the condenser and evaporator ( $\mathrm{PhD}$ thesis). Atatürk University Graduate School of Natural and Applied Science, Department of Mechanical Engineering, Turkey.

Çakır, U. \& Çomakli, K. (2011). Energetic and exergetic comparison of water-water and water-air heat pumps. Proceedings of the 2011 International Conference on Water, Energy and Environment (ICWEE) 2011, Sharjah, UAE, pp. 379385.

Çomakli, K. \& Çakır, U. (2011). A comparative study of vapour compression refrigeration systems under air to air and air to water mode. Proceedings of the 2011 International Conference on Water, Energy and Environment (ICWEE) 2011, Sharjah, UAE, pp. 373-378.

Dinçer, I. \& Rosen, M. A. (2007). Exergy, environment and sustainable development $\left(1^{\text {st }}\right.$ ed.) Burlington Elsevier Science.

Kavanaugh, S. P. (1989). Design considerations for ground and water source heat pumps in southern climates. ASHRAE Transactions, 95(1), 1139-1149.

Kavanaugh, S. P. \& Pezent, M. C. (1990). Lakewater applications of water-to-air heat pumps. ASHRAE Transactions, 961, 813-820.

Kavanaugh, S. P., Woodhouse, J. G., \& Carter, J. R. (1991).Test results of water-to-air heat pumps with high cooling efficiency for ground-coupled applications. ASHRAE Transactions, 97, 895-901.

Kline, S. J. \& McClintock, F. A. (1953). Describing uncertainties in single-sample experiments. Mechanical Engineering, 75, 3-8.

Liu, Z., Ma, L., \& Zhang, J. (2014). Application of a heat pump system using untreated urban sewage as a heat source. Applied Thermal Engineering, 62, 747-757.

Muthucumaraswamy, R., \& Velmurugan, S. (2013). Heat and mass transfer effects on flow past parabolic started isothermal vertical plate in the presence of first order chemical reaction. Journal of Mechanical Engineering and Sciences, 4, 431-439.

Park, H., Kim, D. H., \& Kim, M. S. (2013). Performance investigation of a cascade heat pump water heating system with a quasi-steady state analysis. Energy, 63, 283294.

Rana, G. C., \& Thakur, R. C. (2012). Effect of suspended particles on thermal convection in Rivlin-Ericksen fluid in A Darcy-Brinkman porous medium. Journal of Mechanical Engineering and Sciences, 2, 162-171.

Rosen, M. A. \& Dinçer, İ. (2004). Effect of varying dead-state properties on energy end exergy analyses of thermal systems. International Journal of Thermal Science, 43(2), 121-133. 
Schibuola, L., Tambani, C., Zarrella, A., \& Scarpa, M. (2013). Ground source heat pump performance in case of high humidity soil and yearly balanced heat transfer. Energy Conversion and Management, 76, 956-970.

Urchueguía, J. F., Zacarés, M., Corberán, M. Á., Martos, J., \& Witte, H. (2008). Comparison between the energy performances of a ground coupled water to water heat pump system and air to water heat pump system for heating and cooling in typical conditions of the European Mediterranean coast. Energy Conversion and Management, 49(10), 2917-23.

Venkataramanamurthy, V. P. \& Kumar Senthil, P. (2010). Experimental comparative energy, exergy flow and second law efficiency analysis of R22, R 436b vapor compression refrigeration cycles. International Journal of Engineering Science, 2(5), 1399-1412.

Waheed, M. A., Oni, A. O., Adejuyigbe, S. B., Adewumi, B. A., \& Fadare, D. A. (2014). Performance enhancement of vapor recompression heat pump. Applied Energy, 114, 69-79. 